\title{
Doxorubicin Regimen
}

National Cancer Institute

\section{Source}

National Cancer Institute. Doxorubicin Regimen. NCI Thesaurus. Code C160025.

A chemotherapy regimen consisting of doxorubicin that may be used in the treatment of soft tissue and uterine sarcomas; rhabdomyosarcomas; anaplastic thyroid, endometrial and breast cancers; and desmoid tumors (aggressive fibromatoses). 